\title{
Cognitive Development, Learning Strategies and Academic Performance in the First Stage of University Education
}

\author{
https://doi.org/10.3991/ijet.v16i20.25167 \\ Ynés Phun-Pat ${ }^{(\mathbb{})}$, Carmen Chauca, Maritza Elizabeth Arones Mayurí, \\ Olga Maria Curro-Urbano \\ Universidad Nacional San Luis Gonzaga, Ica, Perú \\ yphuneunica.edu.pe
}

\begin{abstract}
Undergraduate training continues to be a challenge to train entrepreneurial specialists with research-oriented attitudes. Depending on the level of functional development of the brain, the level of learning will be differ-ent in relation to chronological age. The ACRA learning strategies scales [1] allow verifying the frequency, type of strategy and specific technique used by students, the coding strategies being the most important for effective performance throughout life; although there is an abbreviated and validated version of this scale applicable only at the university level by [2] De la Fuente and Justicia (2003); In the study, the 2001 version of [1] is applied to analyze, according to age, the correspondence between the learning strategies used by the students with their academic performance, as well as to verify if there is a difference by gender, during a period of three years. Technical sheets and final grades of the students were also applied; a multiple linear regression analysis; it is a mixed type investigation. It is observed that the Coding strategies are not used very frequently. In Academic Performance (AR), only $7.85 \%$ of the students obtained a final score of 14 or more, the use score coinciding with scales that measure the same learning strategies. The type of strategies and the age (18-19 years) registered influence the RA and only the Acquisition strategies show a slight rela-tionship with the RA. There is no gender relationship.
\end{abstract}

Keywords-ACRA, Adolescence, Brain development, Effective learning, Effectiveness

\section{$1 \quad$ Introduction}

The first stage of university education is fundamental in the adolescent's life; it runs between childhood and adulthood, it is a stage of change, growth and imbalance [3], the passage from education to higher education level makes the student develop a cognitive maturation that allows him to achieve learning strategies for better academic performance. Men use fewer learning strategies than women [4]; and important [5] since the future professional must assume the need to know how to express himself in writing; especially through scientific writing in which a critical, coherent and systematic 
mental maturity must be shown: selecting the appropriate terms to know how to express your thought. In the undergraduate university training stage, it is necessary for the student to learn to select information based on previous knowledge, making use of strategies that allow them to improve the level of learning [6], even when the programs are taught in a learning environment that supports students' reasoning skills believed to be supported by game-based learning [7].

However, there are still limitations in the academic activities of some: the problems of low performance and failure in studies demonstrate that the application of learning and teaching strategies play a decisive role in the learning process of students [8]. In addition, the student's learning stages from entry to completion must be taken into account and during that journey, what variables or indicators intervene at each point of their active learning [9].

According to results of the frequency of use of learning strategies, [10], in their study of a cross-sectional and correlational quantitative approach, on learning styles and strategies to Health Sciences students applied the ACRA scales of learning strategies by [2] adapted from [1]; 295 students between 16 and 24 years of age.

Students use information acquisition strategies more frequently $(42 \%)$, such as underlining, repetition and re-reading; in second place in frequency of use those of Processing Support (38\%); in third place those of Recov-ery $(37 \%)$ and in last place the Coding strategies $(30 \%)$ that are used to reconstruct the information, make it meaningful and be understood.

[11] Reinforce in their experimental design work with post-test and control group, applied to a group of 40 first-year university students, that Recovery is the set of actions by which the performance of students is better in terms of the amount of information retrieved and therefore, the higher scores refer to better results in the tests or exams applied long-term. In particular, they advocate the primacy of memory for learning, in relation to meaningful learning.

[12] Developed a research with a mixed approach, descriptive-correlational type, cross-sectional and non-experimental design in order to identify the learning strategies used by 294 students from 4 higher education institutions of different careers, between 18 and 24 years of age and establish a relationship with academic achievement. Higherscoring students used greater variety and better strategies than middle-achievers; in those with low performance, the non-use of planning as a metacognitive strategy stood out. The association found between cognitive aspects, affective and motivational components, as well as between metacognitive compo-nents, all directly related to academic performance, is highlighted. In the study, the use of Acquisition strategies predominated, followed by Support, Recovery and, finally, Information Coding strategies, using those that work more on the basic elements to learn than those do that develop autonomy to learn.

The quality of student learning and academic rigor is critical to higher education.[13]; the selection of the best analytical tools by the institution is also important [14]. Autonomous learning has become a key to quality [15]. That is why the interest of the research arises, since the problems of low performance of university students continue, which is possibly due to the limitations in their activities, operations and cognitive resources when faced with a certain task [16]. 
[17] For its evaluation, the ACRA learning strategies scales of [1] were used in its four scales: acquisition of information with 20 items, codification of information with 46 items, information retrieval with 18 items and support for processing. With 35 items. Regarding the academic performance of the students, we worked with the final grades of the third academic semester of the students in the Health Sciences area; shows that it is characterized by having a student population more representative of the female gender, as shown in figure 1.

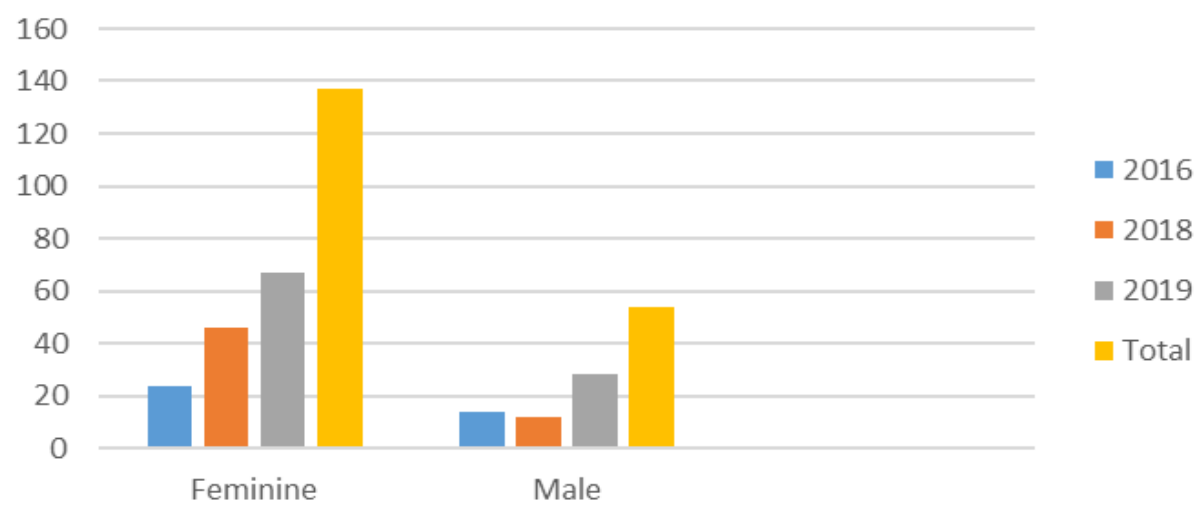

Fig. 1. Distribution by gender according to chronological year (Source: Statistical office of the public university)

For its evaluation, the ACRA learning strategies scales of [1] were used, which allowed to relate the learning strategies most used by students and the result of academic performance, taking into account the indicators (table 1) that associate the study variables.

Table 1. Indicators of the ACRA scale applied to university students

\begin{tabular}{|l|l|c|}
\hline ACRA Scales & \multicolumn{1}{|c|}{ Indicator } & $\mathbf{N}^{\circ}$ items \\
\hline $\begin{array}{l}\text { Acquisition of } \\
\text { Information }\end{array}$ & $\begin{array}{l}\text { Strategies that favor the control and definition of care, iis divided } \\
\text { into attentional and repetition strategies. }\end{array}$ & 20 \\
\hline Information encoding & $\begin{array}{l}\text { The prior knowledge is integrated into broader structures of mean- } \\
\text { ing, which constitute the knowledge base. It is subdivided into } \\
\text { mnemonicization, preparation and organization strategies. They are } \\
\text { used to transform and reconstruct information. }\end{array}$ & 46 \\
\hline Information recovery & $\begin{array}{l}\text { The student optimizes the recovery or recall processes. They are } \\
\text { subdivided into search and response generation strategies. }\end{array}$ & 18 \\
\hline $\begin{array}{l}\text { Support or Support for } \\
\text { processing }\end{array}$ & $\begin{array}{l}\text { It refers to processes of a metacognitive nature that optimize and/or } \\
\text { can also hinder the functioning of learning strategies. The motiva- } \\
\text { tional factor is important. It includes metacognitive and socio-af- } \\
\text { fective strategies. }\end{array}$ & 35 \\
\hline
\end{tabular}


Paper - Cognitive Development, Learning Strategies and Academic Performance in the First Stage of...

\subsection{Cognitive maturation - Learning strategy}

From the epistemological point of view, the ability of the human being to construct a meaningful mental representation of his relationship with the world is a complex process. Role transitions, such as the culmination of education and the assumption of marriage and parenthood, have recently been defined between the ages of 10 and 24 [18]. [19] propose to classify this stage into three age groups, from the point of view of the application of interventions and policies in global health: young (10-14 years), medium (15-19 years) and late (20-24 years). See Table 2.

Table 2. Distribution by age groups

\begin{tabular}{|l|c|c|c|c|c|c|c|c|c|c|c|c|c|c|}
\hline Group & \multicolumn{3}{|c|}{ Middle } & \multicolumn{10}{c|}{ Late } & Total \\
\hline Age & 17 & 18 & 19 & 20 & 21 & 22 & 23 & 24 & 25 & 26 & 27 & 31 & 39 & \\
\hline Fr\% & 7.3 & 34.0 & 30.0 & 11.5 & 6.3 & 2.1 & 3.7 & 1.6 & 1.0 & 0.5 & 0.5 & 0.5 & 0.5 & 100 \\
\hline
\end{tabular}

Source: Statistical office of the public university.

On the other hand, this sociocultural maturation, however, corresponds to a biological one, as regards brain maturation: during adolescence, unique patterns of brain activity are verified between two regions of cognitive and motivational behavior, manifesting a different circuit maturation speed: the adoles-cent's risk behavior (immature capacity for cognitive control, of the prefrontal cortex), showing a special sensitivity to extrin-dry motivational signals (due to the earlier maturation of the striatum ). The matura-tion of the prefrontal cortex ends around the third decade of life [20]; in it are located the centers of planning, concentration, behavioral inhibition, flexible thinking; that is, self-regulation, being so neces-sary to develop them at the present time. Learning, according to Robert Gagné, is considered a perma-nent but modifiable response to the interaction between the person and the environment, determined by biological maturation and repetitive experiential experience. Therefore, enter the information through the senses in the presence of high or low motivation; it is processed, stored in memory, and retrieved when needed. Emotions and motivations are important factors that influence this processing, as well as identifying the ways in which the student learns so that teachers improve their strategies in order to facili-tate the learning process, and students acquire knowledge to improve their academic performance [21]. At the university level, the development of autonomous learning and the making of reflective decisions by the student are gradually being incorporated into the teaching work as an exercise of competent par-ticipation of those in society [22] also considering not only knowledge, but also the affective and social part of the learning process. Neuroscience as a discipline contributes in this aspect related to the func-tioning of the brain [23]. [24], affirm that the learning strategies used are insufficient, mainly focused on the acquisition and coding of information without association with academic performance. Therefore, teachers must innovate strategies focused on the metacognitive development of the student and support them in planning their own learning processes [25]. 
Paper - Cognitive Development, Learning Strategies and Academic Performance in the First Stage of...

\subsection{Academic performance of students}

To measure the result of the academic performance of the university student, and to identify the most used learning strategies, the ACRA was considered, whose indicators are measured to obtain a diagnosis that can serve as the basis for undertaking an Educational project oriented to learning improvement processes [26] and the achievement of the understanding of the content [27]. The learning outcome can be evidenced in the construction of new knowledge [28]. When studying, students use various techniques and skills that are defined as cognitive learning strategies [29]. Students who make use of a greater variety and better learning strategies obtain better grades compared to those in the Intermediate group; likewise, those with low performance do not use planning as a metacognitive strategy.

That is, a strategy implies planning, ordering, organizing or directing a series of actions towards the achievement of an end; In learning, we refer to the set of tactics organized and consciously used by the stu-dent to solve a problem and according to [25], who manage to develop metacognition, consciously assimi-late, applying correctly and at the right time the appropriate strategy for learning. For the student to achieve knowledge depends on many factors, one of them is the teacher's performance, however, it must be taken into account that for deep learning it is necessary for the student to self-manage their learning [30].

To achieve good results, it is necessary to transform the way we teach and learn, a joint effort of all actors aimed at quality education and lifelong learning [31].

The purpose of this study is to analyze cognitive maturation, the learning strategies used by students in the Health Sciences Area, and academic performance in the first stage of university education.

\section{Work development}

\subsection{Material and Methods}

The research design developed was descriptive, retrospective, correlational and cross-sectional. The study population was made up of students from the third academic semester, belonging to the Health Sci-ences Area, of the Public University of the city of Ica - Peru. For the study, three (3) groups were formed, ac-cording to table 3, considering the development of the life stage proposed by [1] y [18] being established as follows:

- Young group: adolescents, 16 years old

- Middle group: adolescents 17, 18, 19 years old

- Late group: adolescents / adults 20 years of age or older. 
Paper - Cognitive Development, Learning Strategies and Academic Performance in the First Stage of...

Table 3. Distribution for age group

\begin{tabular}{|c|c|c|c|c|c|c|c|c|c|c|c|c|c|c|}
\hline Group & \multicolumn{3}{|c|}{ Medium } & \multicolumn{10}{|c|}{ Late } & Total \\
\hline Age & 17 & 18 & 19 & 20 & 21 & 22 & 23 & 24 & 25 & 26 & 27 & 31 & 39 & \\
\hline Total & 14 & 65 & 58 & 22 & 12 & 4 & 7 & 3 & 2 & 1 & 1 & 1 & 1 & 191 \\
\hline Fr (\%) & 7.3 & 34.0 & 30.4 & 115 & 63 & 2.1 & 3.7 & 1.6 & 1.0 & 0.5 & 0.5 & 0.5 & 0.5 & 100 \\
\hline
\end{tabular}

Source: Statistical office of the public university

The Medium group are adolescents who correspond to $71.7 \%$ of the total group under study. There is an absence of a young group (16 years old). The ages of 18 and 19 are the most frequent $(\mathrm{f}=123$ ). The sample was also grouped by gender, as shown in table 4.

Table 4. Gender, greater and lesser frequency of use of learning strategies and their relationship with academic performance

\begin{tabular}{|l|c|c|c|}
\hline \multicolumn{1}{|c|}{$\begin{array}{c}\text { Gender and academic } \\
\text { performance }\end{array}$} & Frequency of use & More frequency & Less frequency \\
\hline $\begin{array}{l}\text { Feminine } \\
\text { academic performance }\end{array}$ & $\begin{array}{c}\text { Cognitive process } \\
\text { Sub strategy }\end{array}$ & $\begin{array}{c}\text { Support } \\
\text { Social interactions } \\
10.90909091\end{array}$ & $\begin{array}{c}\text { Coding } \\
\text { Diagrams } \\
11.03448276\end{array}$ \\
\hline $\begin{array}{l}\text { Male } \\
\text { academic performance }\end{array}$ & Cognitive process & $\begin{array}{c}\text { Support } \\
\text { Motivational } \\
11.125\end{array}$ & $\begin{array}{c}\text { Coding } \\
\text { Diagrams } \\
10.30769231\end{array}$ \\
\hline
\end{tabular}

Source. Statistics and University enrollment section

The variables under study were the age of the students (independent variable), learning strategies and academic performance (dependent variables). In the case of the learning strategies variable, the name adopted by [1] of the cognitive processes that occur in learning is considered, to name the different learn-ing strategies: Acquisition, Coding, Recovery and Support for information processing and for the academ-ic performance variable (AR), the grades obtained at the end of the subject of specific studies are consid-ered, in the vigesimal system made up of the interval $(0-20)$.

Likewise, 2 groups were considered, one, High Level; which corresponds to the top $10 \%$ of the regis-tered grades, that is, from 14 to 20 , and the Non-high Level corresponds to grades below 14; that is, from 0 to 13 .

The data collection instrument was the registration form for the academic performance of the stu-dents, which once the subject was concluded and their semester grades averaged, was used to analyze the correlation of the variables under study. A data sheet was also used to record the student's age, gender, and code.

For the interpretation of the data, a matrix was designed, as shown in table 5; of ranges of frequency of use of learning strategies, based on the scores obtained in the application of the questionnaires, in order to facilitate interpretation and analysis. 
Table 5. Use of strategies based on scores obtained

\begin{tabular}{|l|c|c|}
\hline Age & Scale & Proportion \\
\hline 23 & Acquisition & $3.66 \%$ \\
\hline 25 & Acquisition & $1.05 \%$ \\
\hline 26 & Acquisition & $0.52 \%$ \\
\hline 27 & Acquisition & $0.52 \%$ \\
\hline 17 & Support & 7.33 \\
\hline 18 & Support & 34.03 \\
\hline 19 & Support & 30.37 \\
\hline 22 & Support & 2.09 \\
\hline 24 & Support & 1.57 \\
\hline 39 & Support & 0.52 \\
\hline 20 & Recovery & 11.52 \\
\hline 21 & Recovery & 6.28 \\
\hline 31 & Recovery & 0.52 \\
\hline
\end{tabular}

Source: Result obtained from the application of the instrument

To the students of the Health Sciences area, prior to the application of the instrument, the procedure was explained, as well as the purpose of having reliable results that guarantee the results

\section{$2.2 \quad$ Results}

After having applied the ACRA scales to the selected sample, the result regarding the frequency of use of learning strategies was as follows: in relation to the learning strategy most used by students, the support strategy predominates, with $34.03 \%$ and $30.37 \%$; followed by the recovery strategy with $11.51 \%$, the others vary between zero (0) and seven (7) percent; As can be seen in table 6. It is very important to take into account that the sample is third semester students, and that they develop subjects that correspond to specific studies.

In relation to the academic performance (AR) of the students, according to age group (table 7); It is obtained that in the medium group, made up of adolescents between 17 and 19 years old, the grades are concentrated between 11 and 14, with a frequency of 82 students with a passing grade up to the high level. For grades between 14 and 17, it is a small group of 13 students with high-level scores.

Table 6. Use of strategies based on scores obtained

\begin{tabular}{|l|c|c|c|c|c|}
\hline \multirow{3}{*}{ Strategies } & \multicolumn{5}{|c|}{ Frequency of Use (fc) } \\
\cline { 2 - 6 } & Very low & Low & Middle & High & Very high \\
\cline { 2 - 6 } & $\mathbf{1 0 \%}$ & $\mathbf{2 0 \%}$ & $\mathbf{4 0 \%}$ & $\mathbf{2 0 \%}$ & $\mathbf{1 0 \%}$ \\
\hline Acquisition & $37-42$ & $43-49$ & $50-57$ & $58-62$ & $63-74$ \\
\hline Encoding & $75-90$ & $91-101$ & $102-119$ & $120-131$ & $132-163$ \\
\hline Recovery & $27-40$ & $41-44$ & $45-53$ & $54-58$ & $59-70$ \\
\hline Support & $53-79$ & $80-89$ & $90-103$ & $104-119$ & $120-135$ \\
\hline
\end{tabular}

Sources: Results after applying the instrument 
In relation to the academic performance (AR) of the students, according to age group (table 7); It is obtained that in the medium group, made up of adolescents between 17 and 19 years old, the grades are concentrated between 11 and 14, with a frequency of 82 students with a passing grade up to the high level. For grades between 14 and 17, it is a small group of 13 students with high-level scores.

In the case of the late group, made up of adolescents / adults aged 20 and over; grades are concentrated between 11 and 14, with a frequency of 30 students scoring up to the high level and one student scoring 16 at the high level. The results explain that the students who best use learning strategies are the ones who obtain better results in their academic performance, and support the importance of achieving meaningful learning.

Table 7. Age groups and their relationship with academic performance

\begin{tabular}{ccccccccccccccccccccccc}
\hline R.A. & $\mathbf{0}$ & $\mathbf{1}$ & $\mathbf{2}$ & $\mathbf{3}$ & $\mathbf{4}$ & $\mathbf{5}$ & $\mathbf{6}$ & $\mathbf{7}$ & $\mathbf{8}$ & $\mathbf{9}$ & $\mathbf{1 0}$ & $\mathbf{1 1}$ & $\mathbf{1 2}$ & $\mathbf{1 3}$ & $\mathbf{1 4}$ & $\mathbf{1 5}$ & $\mathbf{1 6}$ & $\mathbf{1 7}$ & $\mathbf{1 8}$ & $\mathbf{1 9}$ & $\mathbf{2 0}$ & Total \\
\hline $\begin{array}{c}\text { Grupo } \\
\begin{array}{c}\text { Medio (f) } \\
\text { Grupo }\end{array}\end{array}$ & 1 & 4 & 1 & 1 & 1 & 2 & 5 & 5 & 6 & 10 & 15 & 34 & 21 & 18 & $\mathbf{9}$ & 2 & 1 & $\mathbf{D}$ & 0 & 0 & 0 & 137 \\
Tardío (f) & 1 & 0 & 1 & 0 & 2 & 0 & 0 & 2 & 6 & 4 & 7 & 20 & 6 & 3 & 1 & 0 & 1 & 0 & 0 & 0 & 0 & 54 \\
Total (f) & 2 & 4 & 2 & 1 & 3 & 2 & 5 & 7 & 12 & 14 & 22 & 54 & 27 & 21 & 10 & 2 & 2 & 1 & 0 & 0 & 0 & 191 \\
$\quad \%$ & 1 & 2.1 & 1 & 0.5 & 1.6 & 1 & 2.6 & 3.7 & 6.3 & 7.3 & 12 & 28 & 14 & 11 & 5.2 & 1 & 1 & 0.5 & 0 & 0 & 0 & 100 \\
\hline
\end{tabular}

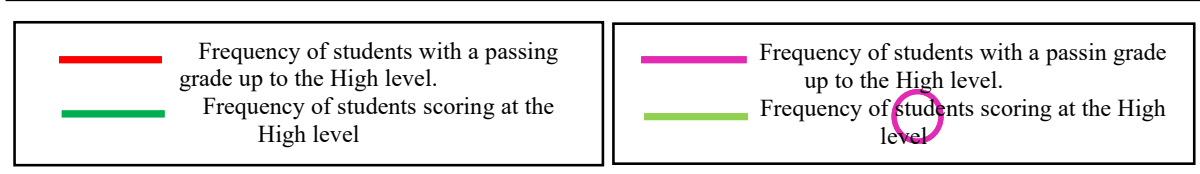

In relation to gender, an analysis was caried out on the use of learning strategies and their academic performance, taking into performance, taking into account the frequency of use, according to table 8 .

Table 8. Gender, greater and lesser frequency of use of learning strategies and their relationship with academic performance

\begin{tabular}{|l|c|c|c|}
\hline $\begin{array}{c}\text { Gender and Academic } \\
\text { Performance (R.A.) }\end{array}$ & Frequency of use & More frequently & Less frequent \\
\hline \multirow{2}{*}{$\begin{array}{l}\text { Feminine } \\
\text { Academic performance }\end{array}$} & Cognitive process & Support & Coding \\
\cline { 2 - 4 } & Sub strategy & Social interaction & Diagrams \\
\cline { 2 - 4 } & & 10.90909091 & 11.03448276 \\
\hline \multirow{2}{*}{$\begin{array}{l}\text { Male } \\
\text { Academic performance }\end{array}$} & Cognitive process & Support & Coding \\
\cline { 2 - 4 } & Sub strategy & Motivational & Diagrams \\
\cline { 2 - 4 } & & 11.125 & 10.30769231 \\
\hline
\end{tabular}

Source: Staticians with data obtained from the application of the instrument

For the study, the gender of the university students was also considered, as shown in table 9; sample made up of 137 female students and 54 male students

As can be seen in Figure 2, support strategies are the most used by all age groups in the study, with a pre-dominance of older students (almost $70 \%$ ). On the other hand, the coding strategies are used by 18 and 20 -year-old students, in a percentage lower than $10 \%$ of the total sample in this work. 
Table 9. Distribution by gender, according to chronological year

\begin{tabular}{|l|c|c|c|c|}
\hline Gender & $\mathbf{2 0 1 6}$ & $\mathbf{2 0 1 8}$ & $\mathbf{2 0 1 9}$ & Total \\
\hline Female & 24 & 46 & 67 & 137 \\
\hline Male & 14 & 12 & 28 & 54 \\
\hline Total & 38 & 58 & 95 & 191 \\
\hline
\end{tabular}

Source: Staticians with data obtained from the application of the instrument

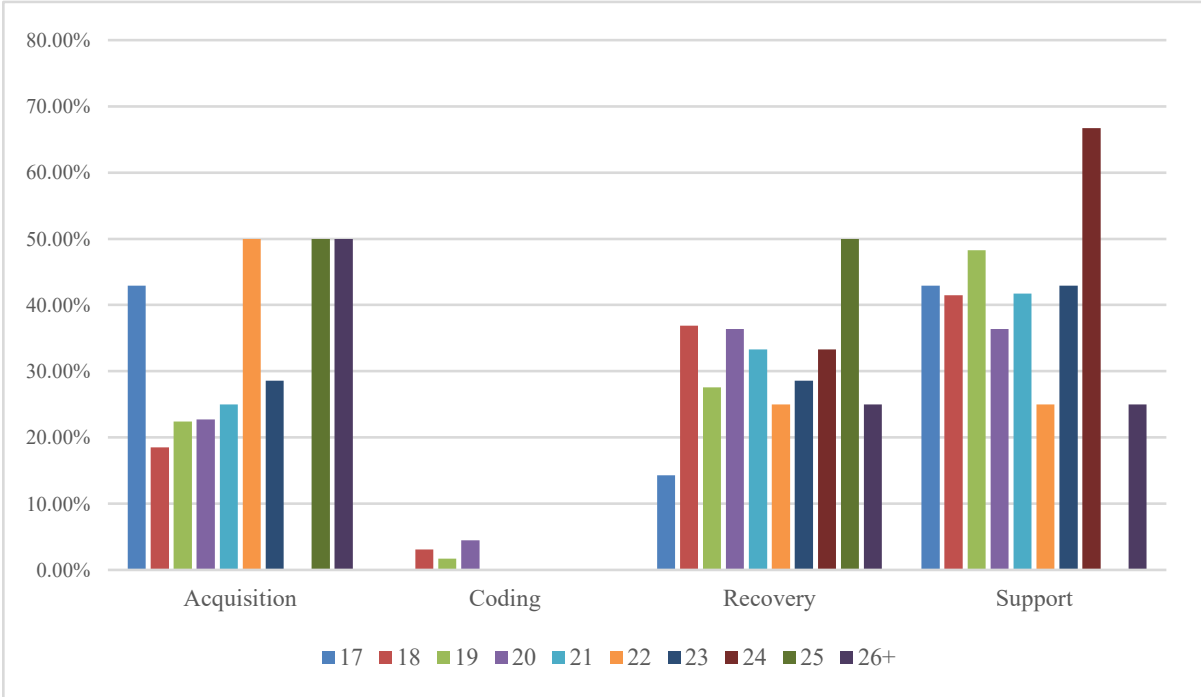

Fig. 2. Distribution of predominant scales according to age (Source: Staticians with data obtained from the application of the instrument)

The ACRA scale, which was the instrument for measuring students' academic performance, considers sup-port strategies, metacognitive strategies, and socio-affective strategies. The first of them is that students have of their own knowledge process, that is, of what to do: declarative knowledge; how to do it: procedural knowledge and when or why to do it: conditional knowledge; and for socio-affective strategies, it is associated with an interest in learning.

According to academic performance groups, Figure 3 shows the distribution of the prevalence of the use of learning strategies. 


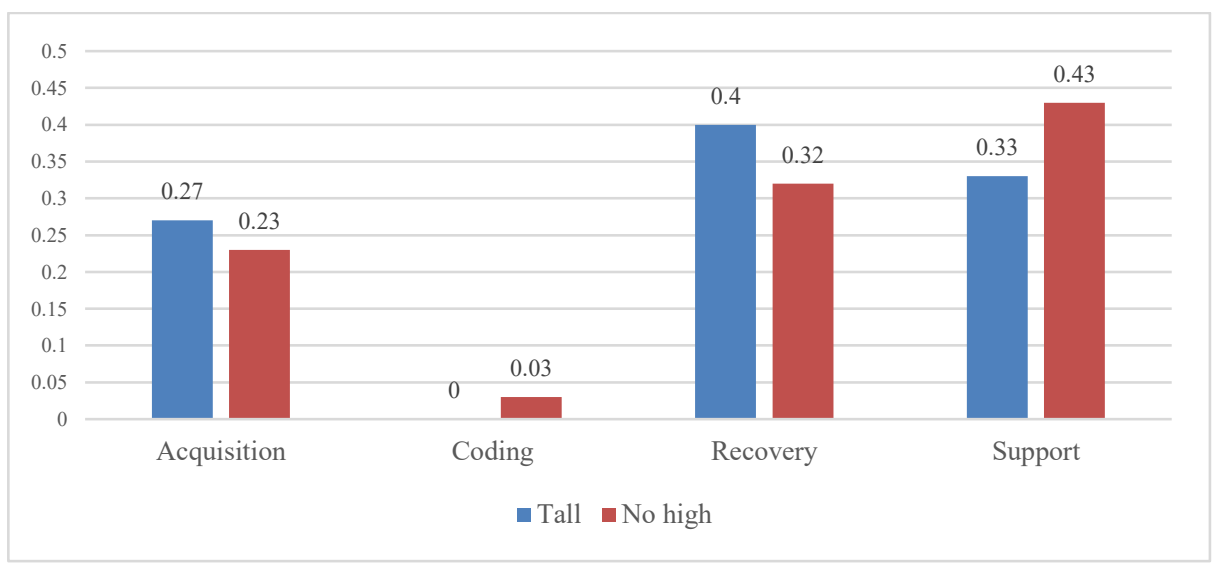

Fig. 3. Average prevalence of use of Scales according to high / not high academic performance

According to the academic performance groups, Figure 4 shows the mean value of the learning strategies scales: Acquisition, Encoding, Retrieval and Support.

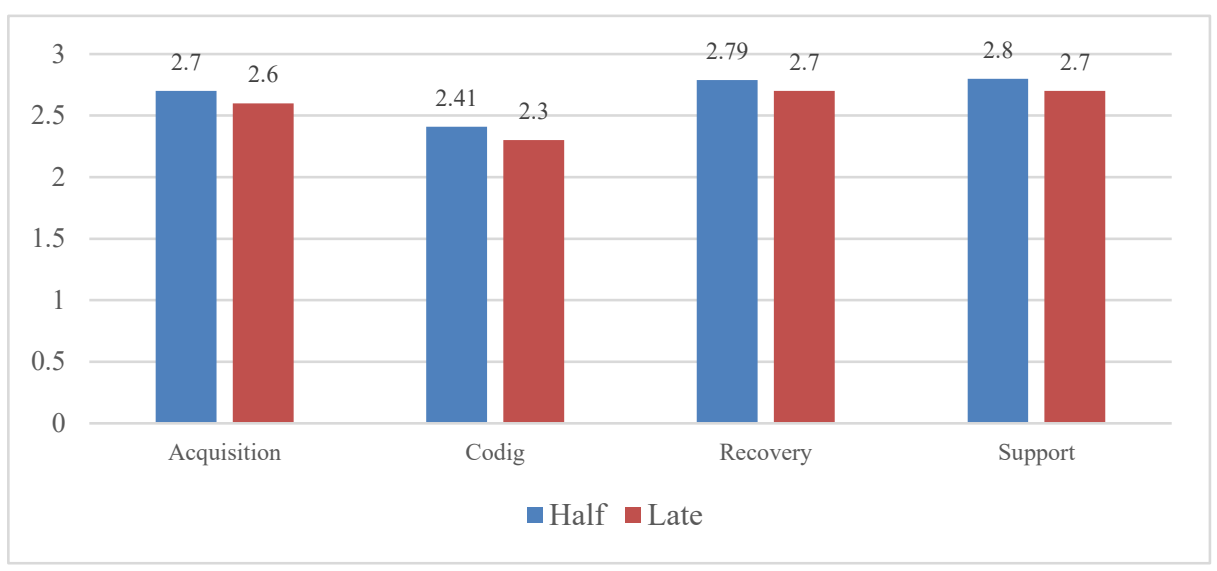

Fig. 4. Average value of use of the learning strategy scales according to academic performance groups.

\section{Discussion}

Considering [1] in which adolescence between 10 to 24 years is currently defined according to the sociocultural role that the individual performs, and with [20] in which, according to a person's brain maturation process, this stage culminates around In the third decade of life, the group corresponding to the present study are mostly adolescents, the ages of 18 and 19 being the most frequent $(f=123)$, corresponding to the Medium classification group. It is at these ages where the practice of learning strategies is most diverse. According to [15], if the student wants to achieve a good autonomous 
learning effect, he must have a great capacity for self-management. The results show that the majority of students have a satisfactory level of autonomous learning, with development potential, if considered in the curricular design of the institution, in accordance with [13] that only an effective curricular design leads to experiences of highquality student-centered learning and with [14] who mention the importance of the selection of the best analytical tools by the University organization.

The adolescents in the study show that the cognitive process where they most frequently use learning strategies is Support for information processing (75.91\%), motivational strategies being the predominant in both age groups; Likewise, it is found that in women learning predominates where they use social interaction strategies and in men those related to motivation (extrinsic, intrinsic and / or escape); possibly these, for the Medium group according to the literature, respond more to those of an extrinsic nature [20] and as a result obtain passing grades more frequently; while for the Late group, those of escape to motivation (to end a stimulus that causes rejection, such as an exam or an evaluation for example).

Both types of motivation can be used to benefit learning, hence the importance of making diagnoses about how the student learns. Coding is the least worked process since it shows little frequency of use of strategies of this type both at the level of gender and in age groups; It is important to know how to "translate" the information that enters the brain into understandable codes, this is directly related to the level of attention in the learning object and this, in turn, in the motivation of the learner (intrinsic motivation).

The entire group studied has a deficiency in the organization of information; It is a study sample that presents little work on the use of self-regulation mechanisms and therefore, autonomous learning [ (Núñez, J. Sola-no, P.; González-Pienda, J. and Rosario, P., 2006); having these mechanisms is necessary in the training processes; In relation to this, this group shows little disposition to scientific writing [3] (Hasanuddin and Sabarti, 2019).

In relation to the group of grades obtained, the coding strategies are the least used and their use is not record-ed in the group of High grades. This means that the obtained marks possibly respond to a temporary learning (retention). In relation to the average value of its use in the age groups, it is observed that for the four cognitive processes, the strategies used occur more frequently in students of the Middle group than in the Late, coinciding with [10] since in addition, this Medium group corresponds to the one with the best grades, from which it can be inferred that the use of a variety of learning strategies is directly related to academic performance.

It differs from that reported by [8], who report for their study with young people between 16 and 24 years of age the most frequent use of Acquisition strategies (42\%) and secondly those of Support (30\%).

It coincides with the same ones that in the last place of frequency of use is the Codification (30\%). Likewise, it differs with [9] since they affirm that the highest scores in the tests correspond to a better performance in the management of Recovery actions; In the present work, these strategies occupy the second place in the average frequency of use $(18.32 \%)$. Likewise, it coincides with [10] for the present study that the Medium group made up of adolescents between 17 and 19 years old uses a greater variety of 
strategies, in direct relation to better grades; Furthermore, the use of meta-cognitive strategies is not recorded, like them; The result on the direct relationship between affective and motivational components and academic performance is shared. Likewise, it is stated that the most used strategies correspond to the dimensions of support for learning and study habits. There is limited use of cognitive and learning control strategies. Considering the time of their educational journey, the results showed that students with higher scores do not necessarily require more strategies during learning than students with lower averages.[2]. The consistent learning styles represent an important component in the learning process at any educational level, considering that it represents the differences in the way in which an individual faces the learning task; therefore, it is essential that the teacher learn to identify the type of learning style that their students have, in order to establish teaching strategies according to the profile of the student they handle [26] Academic programs taught in learning environments reinforce students' reasoning skills, often mo-tivated by game-based learning [5].

\section{Conclusions}

During the teaching-learning activities, the student performs a whole cognitive process to learn, create their own styles and strategies, which the teacher must take advantage of to incorporate new knowledge from the student's collection of previous knowledge. The detailed analysis of the data collection has allowed to obtain the following conclusions:

The differences established in relation to the use of knowledge strategies in the groups of students according to their age (middle group, late group) provide the support to affirm that there is a relationship between age and learning strategies and these with academic performance, it turns out that they were evidenced in the grades of the subjects.

The acquisition strategy reveals a direct relationship with academic performance, that is, students focus their attention on relevant information and on the way they review the contents of the subjects.

The most frequent learning strategies are those to support information processing with $75.91 \%$. It was observed that it has to do with the development of the learning session by the teacher; When it takes into account the learning styles and strategies of its students, developing new methodologies in the teaching process, it allows students to also develop new strategies for the incorporation of knowledge.

It is important to take into account that factors associated with study behavior are involved, the motivational part, where feelings related to personal growth and development are involved, and also consider the social part, that is, how to request support in the face of difficulties. tades., such as relationships with colleagues at the time of integration into a work team.

The effectiveness of the strategies is low in relation to their academic performance. It complements what has been explained above, for the student to achieve good academic performance, he needs to self-regulate his learning, know his learning process, 
the degree of effectiveness he has achieved in his evidence of results, and identify the difficulty to face. new challenges with greater chances of success.

Adolescence is the ideal age to train him in the use of learning strategies applied in his life. Entering the first stage of university training is essential in the professional training of the student; Due to the difference that exists in the teaching process at the higher university level, even more so in the Health Sciences Area, which has been the object of study, where theoretical-practical knowledge is required, essential for their professional training. Therefore, it is necessary for the teacher to support this process of change in the training of university students.

As a final conclusion, the study carried out will serve for subsequent research, even more than in the Peruvian university system, based on University Law No. 30220, it establishes compulsory general, specific and specialty studies, the same as those that are the They take them gradually and that the student must incorporate for each one effective learning strategies that respond to their academic performance, according to the results obtained and shown in previous ones. lines. Likewise, university teachers need to implement new strategies in the development of their teaching practice, focused on the learning subject, creating conditions for students to appropriate knowledge and students to act autonomously, creatively and committed, acquiring or improving learning strategies.

\section{$5 \quad$ References}

[1] Gaxiola J, González S, Contreras Z. and Gaxiola E. (2012) Predictors of academic performance in adolescents with resilient and non-resilient dispositions. Journal of Psychology; 30 (1): 47-75. https://www.redalyc.org/pdf/3378/337829521003.pdf

[2] Rossi Casé, LE, Neer, RH, Lopetegui, MS and Doná, SM (2010). Learning strategies and academic performance according to gender in university students. Journal of PsychologySecond epoch, 11. https://scholar.google.com.ar/citations?view_op=view_citation\&hl= es\&user=gEY64WcAAAAJ\&citation for view=gEY64WcAAAAJ:WF5omc3nYNoC

[3] Hasanuddin D. and Sabarti, E. (2019). Improve students' scientific writing ability through collaborative learning based on blended learning. International Journal of Emerging Technologies in Learning - iJET, 14 (20), 34-43. DOI: https://doi.org/10.3991/ijet.v14i20.11457

[4] Alulema, P., Amancha, P. (2020). Learning strategies applied to the subject internal combustion engines to fulfill learning achievements. Uisrael Scientific Magazine, Vol. 7, N 3. https://doi.org/10.35290/rcui.v7n3.2020.309

[5] Corriena, A., Jaruki, A., Adi, M. (2019). Improve students' reasoning skills in engineering and technology through game-based learning. iJET-vol. 14 (24), 69-80. DOI: https://doi.org/10.3991/ijet.v14i24.12117. https://online-journals.org/index.php/i-jet/article /view/12117/6291

[6] Ureña, Y. and Marroquín, M., (2018). Revolution in education and training for the XXI century, Ed. Instituto Antioqueño de Investigation. Ed- III, Vol.2 edit 3. p. 92-98. ISBN. 978-958-52333-8-6.

[7] Yin-Kin, J and Ifenthaler, D. (2020) Reflections on Different Learning Analytics Indicators for Supporting Study Success", vol. 2, No.2, pp. 4 - 23. https://doi.org/10.3991/ijai. $\underline{\mathrm{v} 2 \mathrm{i} 2.15639}$ 
Paper-Cognitive Development, Learning Strategies and Academic Performance in the First Stage of...

[8] Bertel P. and Martínez R. Learning styles and strategies in Health Sciences students. Psychogente (2012), 15 (28): 323-336. Simón Bolívar University, Colombia. ISSN 0124-0137 EISSN 2027-212X

[9] Pineda, A; Duran, C.; Leiva-Bianchi, M.; Moreno, C.; Muñoz, P. and Oliva, C. (2018) Effect of recovery as a study modality in university students. Journal of Psychology (Santiago 27 (1), 27-37.

[10] Roys, J. and Pérez, A. (2018) Meaningful learning strategies in Higher Education students and their association with academic achievement. Electronic Journal of Research and Teaching (REID,), 19: 145-166. ISSN: 1989-2446. https://dialnet.unirioja.es/servlet/articulo? $\underline{\text { codigo }=6281643}$

[11] Saxena M, and Kasparian Melanie, (2020) Establishing a Sustainable Process to Measure Learner Performance", International Journal of Emerging Technologies in Learning vol.2, No 1, pp. 31-46. https://doi.org/10.3991/ijai.v2i1.13083

[12] Conde, M., Hernández, A, (2019) Data-based education in personal learning environments What about learning beyond the institution ?. ijA [_Vol, 1, N 1,2019. https://doi.org/10.3991 /ijai.v1i1.11041

[13] Li, M., Liao, R., \& Dong, Y. (2019). Adaptive determination of time delay in gray prediction model with time delay. Ingenierie Des Systemes d'Information, iJAI Inernational Journal of Learning Analytics and artificial Intelligence for education, 24 (5), 519-524. https:// doi.org/10.18280/isi.240509

[14] Byrne, M. and Flood, B. (2008). To examine the relationships between background variables and the academic performance of first-year accounting students at an Irish university. Journal of Accounting Education, 26, 202-212. https://doi.org/10.1016/j.jaccedu.2009.02.001

[15] Entwistle, N. and Ramsden, P. (2015). Understand student learning (routine revivals). Routledge. https://doi.org/10.4324/9781315718637

[16] Román, JM and Gallego, S. (1994). ACRA: Learning strategies scales. (2nd ed.) https://scholar.google.com.pe/scholar?lookup=0\&q=Rom\%C3\%A1n, + S. $+\% 26+$ Gallego, + $\underline{\text { R. }+(1994) .+ \text { ACRA-Escala }+ \text { de }+ \text { Estrategias }+ \text { de }+ \text { Aprendizaje \&hl }=\text { es\&as } s d t=0,5 \& \text { as } \text { vis }=1}$

[17] Sawyer SM, Azzopardi PS, Wickremarathne D and Patton GC (2018);. The age of adolescence. Lancet Child Adolesc Health (2: 223-228. https://doi.org/10.1016/s23524642(18)30022-1

[18] Kinghom A, Shanaube K, Toska E, Cluver L and Bekker L. Defining adolescence: priorities from a global health perspective. The Lancet Child Adolesc Health; 2 (5): https://doi. org/10.1016/S2352-4642(18)30096-8

[19] Knapp K, Morton J. (2013), Brain development and executive functions. Encyclopedia of Early Childhood Development; 6 pp. Consulted at: http://www.enciclopediainfantes.com/sites/default/files/textes-experts/es/2480/el-desarrollo-del-cerebro-y-las-servicios$\underline{\text { sociales.pdf }}$

[20] Ruiz Recéndiz, Ma. De Jesús: Álvarez Huante, Claudia Guadalupe; Anguiano Morán, Ana Celia; González Villegas Ruiz. (2019) Academic performance in university students, RELEP1 (3): January, ISSN: 2594-2913. https://doi.org/10.46990/relep.2019.1.3.398

[21] Gloerfeld C and Wrede S. Recommender: Potentials and Limitations for Self-Study in Higher Education from an Educational Science Perspective. International Journal of Learning Analytics and Artificial Intelligence for Education (iJAI), Vol2 (2); 34-45. https://doi.org/10.3991/ijai.v2i2.14763

[22] Tacca Huamán, DR, Tacca Huamán, AL and Alva Rodríguez, MA (2019). Neurodidactic strategies, satisfaction and academic performance in university students. Educational Research Notebooks, 10 (2), 15-32. https://doi.org/10.18861/cied.2019.10.2.2905 
Paper - Cognitive Development, Learning Strategies and Academic Performance in the First Stage of...

[23] Astudillo, HJT, Maldonado, HPA and Torres, MLM (2018). Learning strategies and styles and their relationship with academic performance in educational psychology university students. Social Killkana: Journal of Scientific Research, 2 (2), 9-16.

[24] Ramadhanti, D and Syukur, A. (2019) "Metacognitive weaknesses of students in academics Writing: a preliminary investigation", vol.14, N 11, pp. 41-56. https://doi.org/10. 3991/ijet. v14i11.10213

[25] Ortega F .; Muñoz M .; Vasquez D .; and María Espinoza. Information coding strategies used by Mexican teachers in training processes, (2017); INNOVA research journal, 2 (10), 70-84

[26] Mayorga M. Learning strategies and styles according to the ACRA and VAK models in university students from the city of Ambato (2019), Revencyt; P. 213.

[27] Wong, E; et al. (2019), Psychometric analysis of the learning strategies scales (ACRA) in students from three Peruvian universities; Educare et Comunicare. https://doi.org/10. 35383/educare.v7i1.223

[28] Valle Arias, Antonio and Barca Lozano, Alfonso and González Cabanach, Ramón and Núñez Pérez, José Carlos (1999). The theoretical and conceptual review learning strategies. Latin American Journal of Psychology, 31 (3), 425-461. https://doi.org/10.1002/(SICI) 1520-6629(199805)26:3<229::AID-JCOP4>3.0.CO;2-Q

[29] Tumino, M, Merariz, E., Flores, V, Quinde M. (2018). Approaches and good learning practices in university students. International Journal of Educational Research and Innovation (IJERI), 11, 152-168. ISSN: 2386-4303

[30] Dorninger, C and Schrack, C (2008). "Future Learning Strategy and e Portfolios in Education", vol. 3, No.1, pp. 11-14

[31] University Law N 30220 (2014). Laws. official newspaper El Peruano.

\section{Authors}

Ynés Phun-Pat (Biological Sciences Faculty, Zoology Laboratory), is doctor of education; magister in education, planning and administration of higher education; second specialty in psychopedagogy; in educational projects and culture of peace. Teacher attached to the Faculty of Biological Sciences of the National University San Luis Gonzaga. Specialist teacher in the National Training Program for in-service teachers (PRONAFCAP); Research related to learning strategies; eginning in qualitative research of the research-action type, with the support of ICTs. With studies in neuroeducation. She has research related to invertebrates fauna in the Huacachina Lagoon, Ica and the Region Ica, Peru.

Carmen Chauca (Faculty of Dentistry - carmen.chauca@unica.edu.pe) got the bachelor of Dentistry-UNICA Title of Dental Surgeon-UNICA Magister in DentistryUNICA Doctor of Public Health-UNICA Postgraduate degree in Pediatric DentistryUBA- Argentina Specialty in Oral Radiology and Maxillofacial- UNICA Diploma of study in Senior Management in University Higher Education Centrum Catolica. external evaluator - SINEACE.

Maritza Elizabeth Arones Mayurí (Faculty of Education Sciences and Humanties, President of the Central Commission for Curriculum Reform of the University marones@unica.edu.pe) is a Doctor in Education, Master in Education with a Mention in Administration and Planning of Higher Education, Second Specialty in Teaching 
Methodology. Principal Professor of the Faculty of Education Sciences and Humanities of the National University "San Luis Gonzaga", attached to the Academic Department of Social Sciences. Teacher at the Graduate School of the National University "San Luis Gonzaga" of Ica-Peru and author of some articles in indexed journals

Olga Maria Curro-Urbano (Faculty of Nursing - ocurro@unica.edu.pe) was got the degree in nursing from the Universidad Femenina del Sagrado Corazón, the master's degree in administration and planning of higher education, doctorate in Public Health (UNFV). Specialty in emergencies and disasters. Professor at the San Luis Gonzaga National University in the Faculty of Nursing, of the Department of Community Family Health and Research. She is one member of the internal Licensing and accreditation committees of the Faculty of Nursing, evaluator of labor competence (Mexico 2022. Active member in ReDdolac, Network of Teachers of Latin America and the Caribbean.

Article submitted 2021-06-30. Resubmitted 2021-08-06. Final acceptance 2021-08-06. Final version published as submitted by the authors. 